\title{
JOURNAL OF ADVANCEMENT IN
}

\section{ENGINEERING AND TECHNOLOGY}

Journal homepage: http://scienceq.org/Journals/JAET.php

\section{Modeling of Microwave Curing of Unsaturated Polyester Based Composite Materials as Production Process} Guide

A. O Adeodu ${ }^{1 *}$, C. O Anyaeche ${ }^{2}$, O. O Oluwole ${ }^{3}$

1,2. Department of Industrial and Production Engineering, University of Ibadan.

3. Department of Mechanical Engineering, University of Ibadan.

*Corresponding author: A. O Adeodu

Department of Industrial and Production Engineering

University of Ibadan, Nigeria.

E-mail: femi2001ng@yahoo.com

Received: January 2, 2014, Accepted: January 10, 2014, Published: January 13, 2014.

\section{ABSTRACT}

Modeling of composite curing process is required prior to composite production as this would help in establishing correct production parameters thereby eliminating costly trial and error runs. Determining curing profile temperatures from experiment is a huge challenge which in itself is like re-inventing the wheel of trial and error, when mathematical models of physical, chemical and kinetic properties of the constituent materials could be used in modeling the cure situation to some degree of trust. This work has modeled two types of polymer based composite materials (Aluminum filled polyester and carbon-black filled polyester) representing polymer-metal and polymer-organic composites in order to predict the possible trends during microwave heating with regards to effect of heating rate on degree of cure of the composites.

The numerical models were constructed by taking into account the heat transferred by electromagnetic energy through the resin/filler mixture, as well as kinetic heat generated by cure reaction. The numerical solution of the mathematical models presented were discretized using forward finite differences of the Runge Kuta Method and finally solved using MATLAB ${ }^{\circledR}$ C programming language.

It was observed that Aluminum filled polyester composite responded faster to heat input- induced curing and as such was able to cure faster than polyester -carbon black composite which had much slower cure -heat input response. This implies that in the production process of polymer-organic composites, faster heating rate was necessary to input heat into the process as there was no heat of reaction released during the cure process whereas, polymer-metal composites release heat of reaction contributing to the quick transfer of heat into the metal components causing the metal components to behave as points of adhesion to the polymer matrix thereby necessitating a slower heating rate.

Keyword: Mathematical Modeling, Polymer- matrix Composites, degree of cure, MATLAB®

\section{INTRODUCTION}

\section{Microwave modeling}

In the last decade, the use of composite materials has increased considerably, due to their light- weight and high performance features [1]. Polyester based composites have found many wide spread applications in modern industry like building/ civil constructions e.g. use in interiors of wall panel and roof structure, columns and beams in high ways, bridges and under water structures; Automobile industries e.g. use in vehicle body parts and in Aerospace/Marine industries e.g. components of plane/ ship interiors and body parts. The uses of polyester resins are extremely varied and include luggage, furnishings, appliances, textiles and packages. Also, polyester films are frequently used in packaging and wraps for consumer goods as well as video, audio and computer tapes. This increased demand for composites has led researchers in pursuit of better and faster methods of manufacturing composites. This has led to the use of electromagnetic energy from microwaves and others for processing of composite material. The application of microwave energy to the processing of various materials such as ceramics, metals and composites offers several advantages over conventional heating methods. These advantages include unique micro structure and properties, improved product yield, energy savings, reduction in manufacturing cost and synthesis of new materials [28]. During microwave processing, the potential exists to reduce processing time and enhance product quality as microwaves can transfer 
energy throughout the whole volume of the material. In this case, energy transfer occurs at a molecular level with additional advantages. When microwave energy is in contact with materials having different dielectric properties, it will selectively couple with the higher loss tangent material. Therefore, microwaves can be used for the selective heating of the materials [29].

The simulation and optimization of microwave processing has enjoyed wide spread application in industry as a means to understand and improve product quality. Thermosetting matrix composites fabricated is well served by many continuous and batch processes, all of which share the common and critical step of cure. Cure refers to an irreversible exothermic chemical reaction by which the composite layup is transformed from a soft, multi layered mixture of fibres or particulates and resin, to a hard structural component. The applied energy increases the temperature in the composite, resulting in changes in the molecular structure of the resin and correspondingly, in resin viscosity. The resin then cures and cross- links, producing a rigid structure.

Modeling of the curing process is required to predict the variation of different properties of the material and control the process better. One of the main advantages of the mathematical model is to obtain information about the profiles of temperature and the state of curing developed through the laminate during curing. It is possible but difficult to determine the profile temperature from experiments, and it is more difficult to measure the profile of state of cure within the sample. The high exothermicity of curing reaction associated with the low thermal conductivity of the material is a feature of fundamental importance. As a result, the curing reaction gives rise to high temperature within the resin especially at the center, and high temperature gradients are developed through the sample [24]. These facts may lead to cracking or crazing [24]. Simulation of the process of cure is of great importance from a theoretical point of view in order to gain a fuller insight into the nature of the process, and from a practical point of view to optimize the operational conditions.

New and unexpected physical behaviors such as the hot spot often occur during microwave processing. Therefore, it is necessary to develop simplified mathematical models from which the occurrence of such phenomena can be predicted. Some of the recent developments in the mathematical modeling of microwave heating include:

1. isolation of the heat equation with a non- linear source term assuming the electric field amplitude is constant,

2. coupling of electric field amplitude with temperature obtaining both steady state solutions,

3. control of thermal run- away

4. more extensive work on numerical models for microwave heating process [9-11] [17] [22] [23] [25].

The aim of the work is to model two polymer based composite types polymer-metal and polymer -organic matter composites (represented by Aluminum filled polyester and carbon-black filled polyester respectively) to predict the possible trends during microwave heating with regards to heating rate effect on degree of cure.

\section{MATERIALS AND METHOD \\ Material Composition}

The proposed models involve evaluating the processing of laminates based on two different polyester mixtures composites A and B. System A consists of an othophthalic type, thermosetting (M3903) polyester resin. The composite based on slurry with the following typical parts by weight [24] $25 \%$ propylene glycol, $25 \%$ phthatic anhydride, $16 \%$ malic anhydride, 38\% styrene monomer and 2\% additive making $100 \%$ unsaturated polyester resin, inert and reinforcing fillers with $30 \%$ of aluminum powder material.

In system B, same composition as in system A is maintained with the exception of aluminium which is totally replaced by N762 carbon -black of same composition as in system A.

The following are the set of sequential steps that would be used for making Aluminum and Carbon black- Polyester resin composites.

i. The fabricated moulds are properly prepared and clean.

ii. Correct amount of fillers (Aluminum and Carbon black) are weighed into containers.

iii. Correct amount of polyester resin, hardener and other additives are weighed and mixed together.

iv. Resin and filler are evenly and slowly mixed with the aid of mechanical blender inside a fume cabinet (for safety) in order to ensure a homogeneous composite mixture.

v. Each mixture is poured into moulds and transfered into the oven. Note, before pouring the mixture into the mould, plate surface would be covered with a glossy paper to facilitate easy removal of the final product after solidification [5] [7] [18].

\section{Process Model for Microwave Curing}

Figure 1 shows a schematic component of microwave system for fabricating thermosetting polymer composites. The process consists of exposing the assemblage to a prescribed cure temperature cycle, which transforms the soft filler-resin mixture to a structurally hard product. The dominant physical phenomena involved in the cure process are (a) the chemical reactions affecting the curing process (b) and the electromagnetic energy associated with the heating of the filler/ resin mixtures, including heat of the exothermic cure reaction

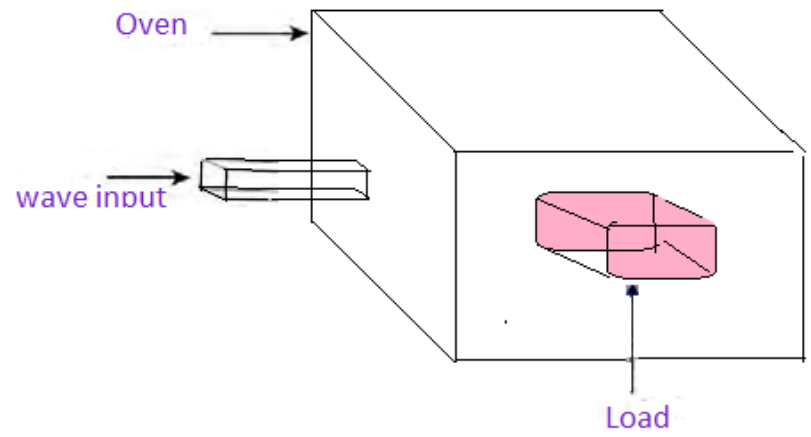


Figure 1. Configuration used in the microwave cavity oven, showing cylindrical shaped load placed in the center of the cavity.

\section{Kinetic Model for Microwave Curing}

Unsaturated polyester resins are commonly used matrix for particulate reinforced composites. Commercial systems are generally supplied as relatively low molecular, unsaturated linear polyesters dissolved in a polymerizable monomer such as styrene, providing cross-linking units by reacting with unsaturation of the resin in a radical addition reaction. The complex chemistry of the unsaturated polyester reactions has been reported in literature [13] [14]. First, the initiator is decomposed leading to the formation of free radicals which progressively reduce the inhibitor concentration. The cure reaction are activated only when the inhibitor is exhausted (induction time); polyester and styrene radicals are first formed and then larger sized active molecules are generated. Finally, the termination reactions progressively reduce the active radical concentration and consequently the polymerization rate. Kenny and Trivisano [15] and Barton [2] have studied the kinetic of the curing reactions of thermosetting polyester by means of differential scanning Calorimetry (DSC), the degree of cure can be modeled simply as an autocatalytic reaction described by the Gonzalez- Romero relationship [6]. It is the most widely used and describes free radical polymerization [16] [19-20]. It is expressed as;

$$
\frac{d \alpha}{d t}=K \alpha^{m}(1-\alpha)^{n}
$$

Kamal [12] and Han et al [8] proposed a slightly more complex kinetic model

$$
\frac{d \alpha}{d t}=K_{1}+K_{2} \alpha^{m}(1-\alpha)^{n}
$$

Where $\mathrm{K}_{1}$ and $\mathrm{K}_{2}$ are rate constants given

$$
K_{i}=A_{i} \operatorname{Exp}\left(\frac{E_{i}}{R T}\right)
$$

$\mathrm{i}=1,2,3,4$

Also, $\mathrm{A}$ is the pre-exponential factor, $\mathrm{E}$ is the activation energy and $\mathrm{R}$ is the gas constant, $\mathrm{m}$ and $\mathrm{n}$ are constant which are independent of temperature.

\section{Thermal Model for Microwave Curing}

The thermal model consists of solving the energy equation in Cartesian co-ordinates for temperature distribution in the composite cross section.

In order to build up a model for the cure in microwave, the assumptions are:

i. Negligible temperature change during flow

ii. Homogeneous and well mixed reaction is achieved

iii. Temperature and degree of cure are functions of time and direction normal to the part surface.

iv. The composite is an infinite medium and can therefore be assumed to be one dimensional.

v. There is constant mould -wall temperature through the entire wall vi. The density $(\rho)$ and the specific heat $(\mathrm{Cp})$ are computed as proper averages of single resin and filler property values as follows.

$\rho_{c}=(1-\varphi) \rho_{r}+\varphi \rho_{f}$

$C p_{c}=\left\{\left(\frac{\rho_{r}}{\rho(1-\varphi)} C p_{r}+\frac{\rho_{f}}{\rho \varphi} C p_{f}\right)\right\}$

Where $\mathrm{c}, \mathrm{r}$ and $\mathrm{f}$ are composite, resin and filler respectively. vii. the power absorbed per unit volume varies linearly with the frequency(f), relative dielectric constant $(\varepsilon)$, loss $\operatorname{tangent}(\tan \delta)$ and the square of the electric field(E) as expressed by Sutton [28],

$P=K f \mathrm{E}^{2} \varepsilon^{\prime} \tan \delta$

viii. The depth of penetration of microwave (Dp) at which the incident power is reduced by half is; [28]

$$
D p=\left(\frac{4.8}{f}\right) \sqrt{\frac{\varepsilon^{\prime}}{\varepsilon^{\prime \prime}}} \ldots \ldots \ldots \ldots \text { (7) }
$$

Where $\varepsilon^{\prime}=$ Dielectric Constant, $\varepsilon^{\prime \prime}=$ Dielectric loss factor, $\mathrm{f}=$ frequency

where $\varepsilon$ ' and $\varepsilon$ " can be dependent on both frequency and temperature, the extent of which depends on the composite sample [28].

The relative dielectric constant and the loss tangent are the parameters that describe the behavior of a dielectric material under the influence of the microwave field. $\varepsilon$ ' mostly determines how much of the incident energy is reflected at the air - sample interface, and how much enters the sample. Tan $\delta$ predicts the ability of the material to convert the incoming energy into heat. During heating, the relative dielectric constant and loss tangent change with temperature.

ix. All material properties (specific heat, density) are

constant during the curing process.

x. Deformation of the material is negligible

xi. No convection and conduction of heat.

\section{Mathematical Modeling}

The heating rate of a material placed in an electromagnetic field depends on several key parameters, more specifically dielectric loss factor of the material. This is described [3] as:

$$
\frac{d T}{d t}=\left\{\left(K f \mathrm{E}^{2} \varepsilon^{\prime}(T)\right) \frac{\tan \delta(T)}{\rho C p}\right\} \ldots \ldots
$$

The specific heat terms show that thermodynamic transitions such as the glass transition temperature and melting of the material will greatly affect the heating susceptibility of the material [27]. The derivation of equation (8) also assumes that convection and conduction losses and heat flux due to chemical reactions are ignored. Equations (6 and 8) are useful 
for judging the effect of electrical properties on microwaves power absorption.

The heat generated by the curing resin, is calculated within the simulation according to equation (9), which assumes that that the heat released by the resin is proportional to the change in the resin's degree of cure as expressed in equation 1. The fractional change in degree of cure is multiplied by the resin's total heat of reaction $(\mathrm{Hr})$. The result is then weighted by the mass fraction of the resin within the composite $\varphi r$.

$$
\frac{d q}{d t}=\varphi_{r} H_{r} \frac{d \alpha}{d t}
$$

\section{Numerical Analysis}

For the numerical solution of the mathematical model presented in equations (1), (8) and (9), the structure of the model can be summarized as follows:

i. Equation (8) was discretized using forward finite differences [21]

ii. At each time interval the value of $\mathrm{dq} / \mathrm{dt}$ is computed from equation (9) by using Runge- Kuta method.

The following initial conditions were used in the model:

Note: initial temperature below 150C will impede the curing process. The ideal temperature ranges from 250C - 350C which should be maintained in the laminate.

Where To and Tc are the initial temperature and curing temperature respectively. The model was solved using MATLAB ${ }^{\circledR}$ C programming language.

Physico - Chemical parameters used as input data for the model

Nomenclature
$\mathrm{A}=$ Pre- exponential factor

$\mathrm{Cp}=$ Specific Heat, (J/g 0c)

$\mathrm{E}=$ Activation Energy $(\mathrm{KJ} / \mathrm{Mol})$

$\mathrm{h}=$ Thickness of laminate $(\mathrm{mm})$

$\mathrm{Hr}=$ Total heat of reaction

$\mathrm{R}=$ Gas Constant $(\mathrm{J} / \mathrm{Mol} \mathrm{k})$

$\mathrm{T}=$ Temperature $(0 \mathrm{C})$

$\mathrm{x}, \mathrm{y}, \mathrm{z}=$ Rectangular Co-ordinates

$\mathrm{K}=$ Reaction Rate Constant (S-1)

$\mathrm{m}$ and $\mathrm{n}=$ Empirical exponents in the cure kinetic model

$\mathrm{q}=$ Heat generated by the curing resin ( $\mathrm{J} / \mathrm{g} \mathrm{sec})$

$\mathrm{t}=$ Time $(\mathrm{sec})$

$\Delta \mathrm{TMax}=$ Maximum temperature difference between the surface and centre of the laminate

$£=$ Electric field strength

$\mathrm{f}=$ Applied frequency

$\mathrm{K}=$ Constant (55.61x 10-12f/m)

$\mathrm{P}=$ Microwave Power dissipation

Greek Symbols

$\alpha=$ Degree of cure

$\rho=$ Density $(\mathrm{Kg} / \mathrm{m} 3)$

$\varphi \mathrm{f}=$ Volume fraction of fibre $(\%)$

$\tan \delta=$ Dielectric loss tangent

$\varepsilon '=$ Dielectric Constant

$\varepsilon "$ " Dielectric loss factor

Subscripts $\mathrm{c}=$ composite

$\mathrm{f}=$ filler

$\mathrm{r}=\mathrm{resin}$

$0=$ initial

For systems A and B, equation (1) was used as kinetic model in describing the polymerization and cross linking reactions. Table 1 shows the values of the input parameters.

Table 1.0 Table Showing the Input Parameters

\begin{tabular}{|l|l|l|l|}
\hline Property & unit & System A & System B \\
\hline Density & $\mathrm{g} / \mathrm{cm}^{3}$ & 1.84 & 1.84 \\
\hline Weight fraction & $\%$ & 30 & 30 \\
\hline Specific heat & $\mathrm{J} / \mathrm{g}^{0} \mathrm{C}$ & 1.72 & 1.35 \\
\hline Heat of reaction & $\mathrm{J} / \mathrm{g}$ & 280 & \\
\hline Activation Energy & $\mathrm{KJ} / \mathrm{mol}^{-1}$ & 140 & 140 \\
\hline Reaction kinetic constant & $\mathrm{Sec}^{-1}$ & 8.9 & 8.9 \\
\hline Reaction order (n) & & 1.35 & 1.30 \\
\hline Reaction order (m) & & 0.65 & 2.7 \\
\hline Pre-exponential factor (A) & & $1.22 \times 10^{14}$ & $1.22 \times 10^{14}$ \\
\hline Tangential loss & & 0.00037 & 0.000303 \\
\hline Electric field strength & & $2.0 \times 10^{4}$ & $2.5 \times 10^{4}$ \\
\hline Constant (K) & $\mathrm{f} / \mathrm{m}^{4}$ & $55.61 \times 10^{-12}$ & $55.61 \times 10^{-12}$ \\
\hline Applied frequency (f) & $\mathrm{GHz}$ & 2.45 & 2.45 \\
\hline Dielectric Loss Factor ( $\left.{ }^{\prime \prime}\right)$ & & 0.001 & 0.001 \\
\hline Dielectric constant ( $\left.\varepsilon^{\prime}\right)$ & & 2.68 & 3.032 \\
\hline Power dissipation (P) & $\mathrm{W} / \mathrm{M}^{3}$ & 1 & 1 \\
\hline Curing cycle Temperature (Tc) & $0^{\mathrm{C}}$ & 106 & 120 \\
\hline
\end{tabular}




\section{RESULTS AND DISCUSSION}

Determination of Cure Characteristics of Systems A and B

Cure characteristic measures the cure response of the samples to increasing heat input through the cure cycle. It is the measurement that is usually contrasted with a reference sample. It essentially provides data about the exothermic and endothermic reactions taking place by monitoring the amount of heat added or extracted from the samples to maintain a cure temperature. Points of measureable heat flows indicate the phase transitions of the material.

It was observed that system A (polyester-Aluminum composite) was fast curing and increased heat input helped drive the curing process forward (Figure 2) whereas system B (Polyester-Carbon black composite) was slow rising with increased heat input. System A degree of cure increased rapidly as heat increased within the system. Therefore, system A was able to attain ultimate cure at approximately 20 minutes. System B had heat accumulation within the system thereby experiencing very low degree of cure until 50 minutes, when it attained full cure. This observation agrees with literature that material with low dielectric loss factor can only absorb limited amount of incident power. Therefore, it was difficult to heat from room temperature to the required temperature [4].

Figure 2 also reveals that the same ultimate degree of cure was obtained for the two systems regardless of characteristic of curing (approx. 99\% and 98\% for system A and $\mathrm{B}$ respectively). The cure cycles for the system are tabulated in the Table 2.

Table 2. Cure cycles for Microwaves method for (A) Polyester-Aluminum composite (B) Polyester- Carbon black composite.

\begin{tabular}{|l|l|l|}
\hline Processing Method & T cure $\left({ }^{0} \mathrm{C}\right)$ & $\begin{array}{l}\text { Actual cure } \\
\text { cycle (min) }\end{array}$ \\
\hline Microwave (system A) & 106 & 20 \\
\hline Microwave (system B) & 120 & 50 \\
\hline
\end{tabular}

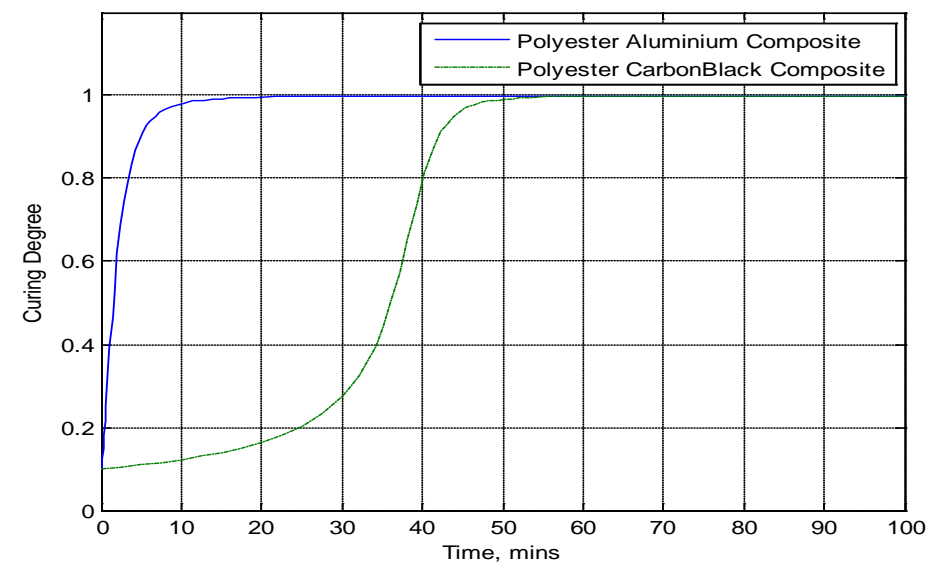

Figure 2. Degree of Cure as a function of curing time for (A) Polyester- Aluminum composite (B) Polyester- Carbon black composite.

Determination of Temperature Profile of Systems A and B

Temperature control and heating rate show the responses of the systems in the curing process to heat as a function of time. It also determines the achievement of temperature stability and uniformity of heating with composites samples.

Figure 3 shows the heating rate profile of the systems during the curing. From this figure, the temperature profile of system A shows much higher heating rate, thus reached curing temperature faster than system $\mathrm{B}$. The vast difference in heating rate between the two systems was due to the difference in the dielectric constant $\left(\varepsilon^{\prime}\right)$ of the materials. System A with higher dielectric constant has invariably initiated higher electric field strength thus, higher heating rate [26]. Figure 3 also shows that there were gradual increases in temperature as a function of time for system B curing compared to system A. This indicated that the process control developed for the microwave power system was able to achieve temperature stability and uniformity of heating in the composite system A compared to B. it is assumed at the end of curing cycles as the systems became cured, the temperature profile gradually decreased. This decrease was most likely due to the decrease in the dielectric loss factor $(\varepsilon$ ') as the polymer structure became a rigid network and also insufficient microwave power being available to maintain temperature [30]. The rigid network structure hindered the polar group motion resulting in less interaction between the electric field and the molecules.



Figure 3. Temperature Profile during curing of system (A) Polyester- Aluminum composite (B) Polyester- Carbon black composite at different cure temperature under microwave heating

\section{CONCLUSIONS}

i. Better control of temperature was observed during the microwave curing of Polyester-Aluminum composite as compared to polyester- Carbon black composite

ii. Similar ultimate degree of cure $(\alpha)$ was obtained from both composite systems using microwave method.

iii. Polyester-Aluminum composite reached ultimate cure faster than polyester- Carbon black composite showing that rigid temperature control procedures must be developed for the production of both composites to suit their cure characteristics.

\section{REFERENCES}

1. Adnan. A, Abdul Razak Al Salem, Najat j. Salah and Hassen Sh. Majdi (2010). Tikrit Journal of Engineering Sciences. , 12(2),118-138. 
2. Barton J. M., (1985) "The application of differential scanning Calorimetry (DSC) to the study of epoxy resin curing reaction", Advance Polymer Science Vol. 72, Pp $111-154$.

3. Chen M., Siochi E. J., Ward T. C and McGrath J. E., (1993). Journal of Polymer Engineering and Science. 33,1092

4. Das S., Mukhopadhyay A. K., Datta S., and Basu D., (2008). An Overview of Prospects of Microwave Processing. Bull and Material Science. 32(1),1-13.

5. Dave R., Kardos J. L. and Dudukovic M. P., (1987). Journal of Polymer Composites. 8, 29.

6. Gonzalez-Romero V. and N. Casillas., (1989). "Polymer Engineering and Science" Vol. 29, Pp5.

7. Halpin J. C., Kardos J. L., and Dudukovic M. P., (1983). Pure \& Appl. Chem. 55, 893-906.

8. Han C. D., Lee D. S., and Chin H. B., (1986). Journal of Polymer Engineering and Science.26, 393-404.

9. Hill J. M and Jennings M. J (1993). Apply Mathematical Model. 17, 369

10. Hill J. M and Marchant T. R (1996). Apply Mathematical Model 20, 3.

11. Hill J. M and Pincombe A. H (1991) Journal of Aust. Math. Soc. Ser. B33 290

12. Kamal M. R. and S. Sourour, (1973). "Kinetics and Thermal Characterization of Thermoset Cure", Polymer Engineering and Science, 13(1), 59-64

13. Kenny J. M., Apicella A., and Nicolais L. A., (1989). Poly. Eng. Sci., 9,973-83.

14. Kenny J. M., A. Maffezzoli and L. Nicolais, (1990) "A model for the thermal chemo-rheological behavior of thermoset processing (II) unsaturated polyester based composites", Composites Science and Technology, 38, 339-358,

15. Kenny J. M. and A. Trivisano, (1991). Polymer Engineering and Science. 31, 1426.

16. Kosar V and Z. Gomzi (2001)."Thermal Effects of Cure Reaction for Unsaturated Polyester in Cylindrical Moulds", Chem. Biochem. Eng., Q., 15, 3, 101-108.

17. Kriegsmann G. A (1992). Mater. Res. Soc. Symp. Proc. 269, 257

18. Kwok Yeung Peter Wong, (2012). Measurement of Mechanical Electrical and Thermal Properties of Glass
Powder Reinforced Epoxy Composites. A MSc dissertation. University of Southern Queensland. Australia.

19. Lam W. K., H. P. Plaumann and T. Tran., (1990)."An Improved Kinetic Model for the Autocatalytic Curing of Styrene-Based Thermoset Resins.", Journal Applied Polymer, 41,3043- 3057

20. Lee W. I and Springer G. S (1984). Journal of Composite Material.18, 387

21. Mathews J. H., and K. D. Fink, (1999). Numerical Methods Using MATLAB. 3rd Ed., Prentice Hall.

22. Mercado G. A, Luce B. P and Xin J., (2002) IMA Journal of Apply Mathematics.67, 419

23. Moitsheki R. J and Makinde O. D., (2007) Appl. Math. \& Comput. 191, 308

24. Nixon J. A and Hutchinson J. M., (1985). Analysis of the Cure of Sheet Moulding Compound. Development of the Model. Plastic and Rubber Processing Application, 5: 349-357

25. Pusatcioglu S. Y., Hassler J. C., Fricke A. L., and. Mcgee H. A., (1980). Journal of Apply Polymer Science, 25, 81-93.

26. Santos T., Costa L. C., Valente M., Monteiro J. and Sousa J, (2010). 3D Electromagnetic Field Simulation in Microwave Oven: A Tool to control thermal runaway. Extract from the proceeding of COMSOL Conference Paris.

27. Suckley, D.R. (2000). Microwave Processing of the Araldite LY5052:HY5052 Epoxy Resin System. M. Sc. Dissertation. UMIST, United Kingdom

28. Sutton, W.H., (1989). Microwave Processing of Ceramics, Ceramic Bulletin, 68(2), 376-86.

29. Thostenson, E.T. and Chou, T.W. (2001). Microwave and conventional curing of thick-section thermoset composite laminates: experiment and simulation, Polymer Composites 22,197-212.

30. Thostenson E. T and Chou T. W, (2001). Microwave and conventional curing of thick-section thermoset composite laminates: experiment and simulation, Polymer Composites 22 Pp 197-212.

31. Yussoff R., Aroua M., Nesbitt A.and Day R. J., (2007). Curing of Polymeric Composite Using Microwave Resin Transfer Moulding (RTM). 